\title{
Impaired TRPM3-dependent calcium influx and restoration using Naltrexone in natural killer cells of myalgic encephalomyelitis/chronic fatigue syndrome patients
}

Natalie Eaton-Fitch 1,2,3*0 , Stanley Du Preez ${ }^{1,2,3}$, Hélène Cabanas ${ }^{3,4}$, Katsuhiko Muraki ${ }^{3,5}$, Donald Staines ${ }^{2,3}$ and Sonya Marshall-Gradisnik ${ }^{2,3}$

\begin{abstract}
Background: Myalgic encephalomyelitis/chronic fatigue syndrome (ME/CFS) is a serious disorder of unknown aetiology. While the pathomechanism of ME/CFS remains elusive, reduced natural killer (NK) cell cytotoxic function is a consistent immunological feature. NK cell effector functions rely on long-term sustained calcium $\left(\mathrm{Ca}^{2+}\right)$ influx. In recent years evidence of transient receptor potential melastatin 3 (TRPM3) dysfunction supports the hypothesis that ME/CFS is potentially an ion channel disorder. Specifically, reports of single nucleotide polymorphisms, low surface expression and impaired function of TRPM3 have been reported in NK cells of ME/CFS patients. It has been reported that mu ( $\mu$ )-opioid receptor ( $\mu \mathrm{OR}$ ) agonists, known collectively as opioids, inhibit TRPM3. Naltrexone hydrochloride (NTX), a $\mu \mathrm{OR}$ antagonist, negates the inhibitory action of $\mu \mathrm{OR}$ on TRPM3 function. Importantly, it has recently been reported that NTX restores impaired TRPM3 function in NK cells of ME/CFS patients.
\end{abstract}

Methods: Live cell immunofluorescent imaging was used to measure TRPM3-dependent $\mathrm{Ca}^{2+}$ influx in NK cells isolated from $n=10$ ME/CFS patients and $n=10$ age- and sex-matched healthy controls (HC) following modulation with TRPM3-agonist, pregnenolone sulfate (PregS) and TRPM3-antaognist, ononetin. The effect of overnight (24 h) NTX in vitro treatment on TRPM3-dependent $\mathrm{Ca}^{2+}$ influx was determined.

Results: The amplitude $(p<0.0001)$ and half-time of $\mathrm{Ca}^{2+}$ response $(p<0.0001)$ was significantly reduced at baseline in NK cells of ME/CFS patients compared with HC. Overnight treatment of NK cells with NTX significantly improved TRPM3-dependent $\mathrm{Ca}^{2+}$ influx in ME/CFS patients. Specifically, there was no significance between HC and ME/CFS patients for half-time response, and the amplitude of $\mathrm{Ca}^{2+}$ influx was significantly increased in ME/CFS patients $(p<0.0001)$.

Conclusion: TRPM3-dependent $\mathrm{Ca}^{2+}$ influx was restored in ME/CFS patients following overnight treatment of isolated NK cells with NTX in vitro. Collectively, these findings validate that TRPM3 loss of function results in altered $\mathrm{Ca}^{2+}$ influx supporting the growing evidence that ME/CFS is a TRP ion channel disorder and that NTX provides a potential therapeutic intervention for ME/CFS.

${ }^{*}$ Correspondence: ncned@griffith.edu.au

'School of Pharmacy and Medical Sciences, Griffith University, Gold Coast, Australia

Full list of author information is available at the end of the article original author(s) and the source, provide a link to the Creative Commons licence, and indicate if changes were made. The images or other third party material in this article are included in the article's Creative Commons licence, unless indicated otherwise in a credit line to the material. If material is not included in the article's Creative Commons licence and your intended use is not permitted by statutory regulation or exceeds the permitted use, you will need to obtain permission directly from the copyright holder. To view a copy of this licence, visit http://creativecommons.org/licenses/by/4.0/. The Creative Commons Public Domain Dedication waiver (http://creativeco mmons.org/publicdomain/zero/1.0/) applies to the data made available in this article, unless otherwise stated in a credit line to the data. 
Keywords: Myalgic encephalomyelitis, Chronic fatigue syndrome, Natural killer cells, Transient receptor potential melastatin 3, Calcium, Naltrexone

\section{Background}

Transient receptor potential (TRP) channels are a superfamily of polymodal sensors present in many tissue and cell types, and their involvement in sensory reception is well known [1]. The TRPM3 (melastatin) channel acts as a non-selective cation channel that possesses high permeability for calcium $\left(\mathrm{Ca}^{2+}\right)[2,3]$. The activation of TRPM3 channels leads to a cascade of intracellular pathways to facilitate cell function in both excitable and nonexcitable cells [4]. TRPM3 shares the typical structure of all TRP channels with six transmembrane domains with both the $\mathrm{N}$-terminal and $\mathrm{C}$-terminal domains located within the cytosol. The endogenous neurosteroid, pregnenolone sulfate (PregS) $\left(\mathrm{EC}_{50}=12-32 \mu \mathrm{M}\right)$ is commonly used in research to activate TRPM3 ion channel activity to induce an increase in intracellular $\mathrm{Ca}^{2+}$ concentration [5] while ononetin $\left(\mathrm{IC}_{50}=0.2-2 \mu \mathrm{M}\right)$ rapidly and reversibly inhibits PregS-evoked ionic currents [6]. Changes in the function or activation of TRPM3 would result in changes to $\mathrm{Ca}^{2+}$ and as a consequence impacts cell function.

$\mathrm{Ca}^{2+}$ is a versatile, universal secondary messenger that facilitates vital biological processes in all cell types. $\mathrm{Ca}^{2+}$ ions are in part responsible for promoting intracellular signalling pathways, cell differentiation and proliferation, programmed cell death and transcriptional events in many cell types [7]. The intracellular concentration of $\mathrm{Ca}^{2+}\left(\left[\mathrm{Ca}^{2+}\right]_{\mathrm{I}}\right)$ is tightly controlled in homeostatic conditions. Growing evidence suggests that the expression of TRPM3 on natural killer (NK) cells indicates a role of TRPM3 in the regulation of $\mathrm{Ca}^{2+}$ in immune cells [8-11]. In addition to the processes described above, the influx of $\mathrm{Ca}^{2+}$ in NK cells is important for microtubule rearrangement resulting in granule polarisation, formation of the immune synapse, release of cytolytic granules and granzyme dependent target cell death $[12,13]$. Therefore, disturbances in $\mathrm{Ca}^{2+}$ homeostasis in lymphocytes can adversely impact immune cell functions and consequentially lead to immune diseases and immunodeficiencies [14].

Myalgic encephalomyelitis/chronic fatigue syndrome (ME/CFS) is a severe multisystemic illness hallmarked by post-exertional neuroimmune exhaustion accompanied by a range of symptoms that are broadly categorised as neurological, immunological, cardiovascular, gastrointestinal and endocrinological $[15,16]$. The pathomechanism underlying ME/CFS is unknown, however immunological disturbances have been well reported with emphasis on NK cell dysfunction [17]. In 2016, five single nucleotide polymorphisms (SNPs) were identified in the TRPM3 gene (rs6560200, rs1106948, rs12350232, rs11142822, rs1891301) in NK cells from ME/CFS patient [18]. Subsequently, flow cytometry revealed a significant reduction in surface expression of TRPM3 and preliminary data reported significantly reduced $\mathrm{Ca}^{2+}$ mobilisation in NK cells of ME/CFS patients compared with healthy controls $(\mathrm{HC})[8,9]$. Electrophysiological experiments have demonstrated a loss of TRPM3 ion channel function in NK cells of ME/CFS patients compared with HC $[10,11]$. Thus, there is a growing body of evidence suggesting the pathomechanism of ME/CFS may be a channelopathy $[8,10,19]$. Therefore, a working hypothesis for the pathophysiology of ME/CFS is that impaired TRPM3 ion channel function limits the influx of $\mathrm{Ca}^{2+}$ and downstream signalling pathways, and consequentially impedes cell function.

Currently, no universal treatment exists for ME/CFS, instead treatment is aimed at alleviating targeted symptoms by administering central nervous system (CNS) stimulants, sleeping medications and analgesics [20]. Importantly, TRPM3 has been identified as a thermosensitive and nociceptive channel implicated in detecting pain and heat produced during inflammation with emphasis on heat hyperalgesia and general pain transmission in the CNS [21]. Moreover, the wide spread expression of TRPM3 in areas of the CNS including the cerebrum, brain stem, hypothalamus and hippocampus suggests a role in muscle coordination, cognitive behaviour and memory $[8,22]$. These functional properties overlap considerably with symptoms of ME/CFS as epidemiological data has shown ME/CFS patients experience sensitivity for pain with up to $94 \%$ of patients reporting muscle aches and pains while $84 \%$ report multi-joint pain [23]. Therefore, TRPM3 dysfunction provides a potential therapeutic target for the treatment of ME/CFS.

Recent research has found that naltrexone (NTX) at low doses (LDN) improves the symptoms of ME/CFS [24]. Electrophysiology experiments in ME/CFS patients reported a potential benefit in restoring impaired TRPM3 ion channel activity following treatment of isolated NK cells with NTX [25]. Interestingly, NTX is a long-lasting antagonist to a subfamily of receptors known as opioid receptors $(\mathrm{OR})$ used to treat opioid and alcohol dependence [26]. $\mathrm{Mu}-\mathrm{OR}(\mu \mathrm{OR})$ belong to a large and diverse group of membrane receptors known as $\mathrm{G}$ protein coupled receptors (GPCRs). GPCRs are widely distributed 
in the human body where activated G proteins can interact and regulate many effectors or molecules such as $\mathrm{Ca}^{2+}$ sensors, ion channels and protein kinases [27]. The activity of TRPM3 can be inhibited by the activation of $G$ protein subunits and direct binding of these subunits to the channel [28]. NTX specifically inhibits the $\mu \mathrm{OR}$, thus negating these inhibitory effects on TRPM3 [2830]. Whole-cell patch clamp electrophysiology has been used to investigate the function of TRPM3 ion channels in ME/CFS patients who regularly administered LDN. TRPM3 function yielded similar results between ME/ CFS patients taking LDN and HC [31]. As NTX restored TRPM3 ion channel function, it may in turn re-establish $\mathrm{Ca}^{2+}$ influx in NK cells leading to normalised downstream signalling pathways and immune functions.

While the function of TRPM3 ion channels have been determined in NK cells of ME/CFS patients using the whole-cell patch clamp technique, this current investigation was designed as a complementary study to evaluate $\mathrm{Ca}^{2+}$ influx in order to validate the loss of TRPM3 channel function using an additional method to ensure full potential of research. We aimed, for the first time, to investigate the speed and maximum response of TRPM3dependent $\mathrm{Ca}^{2+}$ influx in ME/CFS patients compared with $\mathrm{HC}$ using an immunofluorescent technique. This current investigation provides further insights of the potential therapeutic role of NTX by examining the effect of overnight in vitro treatment on TRPM3-dependent $\mathrm{Ca}^{2+}$ influx.

\section{Methods}

\section{Recruitment}

ME/CFS patients and $\mathrm{HC}$ were contacted using the National Centre for Neuroimmunology and Emerging Diseases (NCNED) patient database. Participants were screened in accordance to the Canadian Consensus Criteria (CCC) and International Consensus Criteria (ICC) case definitions for ME/CFS using a comprehensive online questionnaire. ME/CFS patients were included if they met the CCC or ICC case definitions for diagnosis and reported being diagnosed by a physician. Potential eligible participants were invited to volunteer in this project. Of those contacted using the NCNED database, $10 \mathrm{ME} / \mathrm{CFS}$ patients from South-East Queensland were invited to volunteer in this project. ME/CFS patients were age- and sex-matched with $\mathrm{HC}$. The $\mathrm{HC}$ group was defined as those who have not been diagnosed with any underlying illness and are non-fatigued. All participants were aged between 18 and 60 years, had a BMI between 18.5 and $29.9\left(\mathrm{~kg} / \mathrm{m}^{2}\right)$ and were non-smokers.

Participants were excluded if they reported a history of alcohol abuse, cardiovascular disease, diabetes, metabolic syndrome, thyroid disease, malignancies, insomnia, chronic fatigue, and if they were pregnant or breastfeeding. Furthermore, all participants were excluded if they reported the use of pharmacological agents that directly or indirectly interfere with TRPM3 ion channel function as well as $\mathrm{Ca}^{2+}$ signalling and immune cell activity. This investigation was approved by the Gold Coast Human Research Ethics Committee (HREC/2019/QGC/56469) and Griffith University Human Research Ethics Committee $(\mathrm{GU} / 2019 / 1005)$.

\section{Participant data collection and sample collection}

All participants completed an online questionnaire to provide sociodemographic background, medical history, medications, and symptom history for ME/CFS patients. The 36-item short form health survey (SF-36) and World Health Organization (WHO) Disability Assessment Schedule (DAS) were used to determine level of disability and quality of life (QoL) [32,33].

Between 7:00 a.m. and 11:00 a.m. at collection locations including Griffith University, Royal Brisbane and Women's Hospital, Robina Hospital, Toowoomba Base Hospital, Sunshine Coast University Hospital and Tweed Hospital, a total of $84 \mathrm{ml}$ of whole, non-fasted blood was collected from consenting participants into ethylenediaminetetraacetic acid (EDTA) tubes via venepuncture by a qualified phlebotomist. Four ml of EDTA whole blood was used for red blood cell count, white blood cell count and granulocyte cell count within four hours of blood collection for each participant.

\section{Peripheral blood mononuclear cell and natural killer cell isolations}

Samples were deidentified using a unique code and delivered to the laboratory. Eighty $\mathrm{ml}$ of blood was used for peripheral blood mononuclear cells (PBMC) isolation by density gradient centrifugation using Ficoll (GE Healthcare, Uppsala, Sweden) as previously described [34]. PBMCs were stained with trypan blue (Invitrogen, Carlsbad, CA, USA) to determine cell count and cell viability. PBMCs were adjusted to a final concentration of $5 \times 10^{7}$ cells/ml for NK cell isolation.

NK cells were isolated by immunomagnetic selection using the EasySep Negative Human NK cell Enrichment Kit (Stem Cell Technologies, Vancouver, BC, Canada). Approximately $2.5-4 \times 10^{6}$ cells NK cells were isolated and used for $\mathrm{Ca}^{2+}$ imaging experiments. NK cell purity was defined by $\mathrm{CD} 3^{-} \mathrm{CD} 56^{+}$surface expression using flow cytometry (Additional file 1: Figure S1). Specifically, NK cells were incubated for $20 \mathrm{~min}$ at room temperature in the presence of CD3 PE-Cy7 $(5 \mu \mathrm{l} /$ test $)$ and CD56 APC $(20 \mu \mathrm{l} /$ test) monoclonal antibodies (Becton Dickinson [BD] Biosciences, San Jose, CA, USA). Cells were acquired at 10,000 events using the Accuri C6 flow 
cytometer (BD Biosciences, San Diego, CA, USA). The average NK cell purity (\%) for this study was $86.73 \pm 9.71$ (Additional file 1: Figure S2).

\section{Interleukin-2 stimulation and in vitro drug treatment}

Freshly isolated NK cells $\left(\sim 4.5 \times 10^{6}\right.$ cells $)$ were stimulated with $20 \mathrm{IU} / \mathrm{ml}$ of recombinant human IL-2 (Miltenyi Biotech, BG, Germany) and treated with 200uM NTX (Sigma-Aldrich, St. Louis, MO, USA) for $24 \mathrm{~h}$ at $37^{\circ} \mathrm{C}$ with 5\% $\mathrm{CO}_{2}$ in Roswell Park Memorial Institute Medium (RPMI)-1640 (Invitrogen Life Technologies, Carlsbad, CA, USA) supplemented with $10 \%$ fetal bovine serum (FBS) (Invitrogen Life Technologies, Carlsbad, CA, USA). The use of IL-2 is designed to support the culture of NK cells overnight.

\section{Calcium imaging}

NK cells $\left(2.0 \times 10^{5} \mathrm{NK}\right.$ cells/well $)$ were immobilised using Corning ${ }^{\circledR}$ Cell-Tak ${ }^{\text {TM }}$ Cell and Tissue Adhesive (BD Biosciences, San Jose, CA, USA) coated 24 well $\mu$-plate (Ibidi, Lochhamer Schlag, Germany). NK cells were incubated for $30 \mathrm{~min}$ at $37^{\circ} \mathrm{C}$ with $1 \mu \mathrm{M}$ Fluo-8 (Abcam, Cambridge, UK) with $0.02 \%$ Pluronic F127 (Thermofisher, Waltham, Massachusetts, United States). Cells were then washed in indicator free solution and incubated for a further $30 \mathrm{~min}$ at room temperature to allow for de-esterification of Fuo-8 AM. All experiments were performed at room temperature $\left(23 \pm 2{ }^{\circ} \mathrm{C}\right)$ and in a $1.8 \mathrm{mM} \mathrm{Ca}^{2+}$ solution. The $\mathrm{Ca}^{2+}$ solution was prepared in milliQ water and contained: $\mathrm{NaCl} 140 \mathrm{mM}, \mathrm{KCl} 5.4 \mathrm{mM}, \mathrm{CaCl}_{2} 1.8 \mathrm{mM}$. $\mathrm{MgCl}_{2} 1.0 \mathrm{mM}$, HEPES $10 \mathrm{mM}, \mathrm{NaOH}$ was used to adjust $\mathrm{pH}$ to 7.4 and osmolality was adjusted to $300 \mathrm{mOsm} / \mathrm{L}$ using D-Glucose.

NK cells were imaged using the Nikon A1R microscope, and fluorescence emissions were monitored using a iXon Life 888 Electron Multiplying CCD camera. Baseline $\mathrm{Ca}^{2+}$ was imaged for 2 min before cells were stimulated with $50 \mu \mathrm{M}$ PregS followed with $1 \mu \mathrm{M}$ ionomycin for 3 min each. Alternatively, due to the natural decline in fluorescence following peak PregS-dependent $\mathrm{Ca}^{2+}$ flux, the effect of ononetin was measured using a separate protocol. In order to desensitize TRPM3 channels, baseline $\mathrm{Ca}^{2+}$ was imaged for $3 \mathrm{~min}$ in the presence of $4 \mu \mathrm{M}$ of ononetin followed by $4 \mu \mathrm{M}$ ononetin $+50 \mu \mathrm{M}$ PregS, followed by $50 \mu \mathrm{M}$ PregS and lastly $1 \mu \mathrm{M}$ ionomycin. $\mathrm{Ca}^{2+}$ flux measurements in response to ononetin was added as supplementary material to demonstrate effective inhibition of $50 \mu \mathrm{M}$ of PregS (Additional file 1: Figure S3). The use of $1 \mu \mathrm{M}$ of ionomycin aligns with previous literature $[9,35,36]$. The concentration of PregS and ononetin was determined using dose response analysis (Additional file 1: Figure S4).
Variations in fluorescence were measured using NIS Research Elements (Nikon, NIS-Elements V5.2, Tokyo, Japan). Three measurements were reported to represent $\mathrm{Ca}^{2+}$ influx. Amplitude value represents the peak of $\mathrm{Ca}^{2+}$ influx curve upon activation by PregS and from this the half-time of maximum (T1/2) response was also determined. The rate of $\mathrm{Ca}^{2+}$ influx was determined using the initial slope of the curve as calculated using OriginLabs. PregS dependent $\mathrm{Ca}^{2+}$ influx measurements were normalised against ionomycin response curves to give the proportion of maximum response.

\section{Chemicals and reagents}

PregS (product code: RDS537650) and ononetin (produce code: RDS514350) were purchased from In Vitro Technologies and stock solutions were prepared at $100 \mathrm{mM}$ in $100 \%$ DMSO and stored according to the suppliers' instructions. NTX (product code: N3136-100MG) was prepared fresh prior to each experiment and reconstituted at $100 \mathrm{mM}$ in distilled water. IL-2 was purchased from Miltenyi Biotec (product code: 130-097-744) stored at 100,000 IU stock in distilled water for up to 1 month. Ionomycin was purchased from Sigma Aldrich (product code: $19657-1 \mathrm{MG}$ ) and resuspended at $10 \mathrm{mg} / \mathrm{ml}$ in $100 \%$ DMSO and stored for up to 1-month at $-20{ }^{\circ} \mathrm{C}$. Fluo-8 was purchased from abcam (product code: ab142773) and stored at $1 \mathrm{mM}$ aliquots for up at one month in 100\% DMSO. Flow cytometric antibodies were purchased from BD Biosciences, CD3 PE-Cy7 (product code: 563423 ) and CD56 APC (product code: 555518).

\section{Statistical analysis}

Shapiro-Wilk test was used to assess normality of distribution of investigated parameters. Additional visual observation of histogram plots was completed. Data presented as mean \pm standard deviation (SD) unless otherwise stated. Differences were tested using the MannWhitney $\mathrm{U}$ non-parametric $\mathrm{T}$ test. Flow cytometry data were exported from Accuri C6 software. Fluorescence and time-course data were exported from NIS-Elements Advanced Research version 5.2. Statistical analysis was done using GraphPad Prism V8 (Graphpad Software Inc., Version 8, La Jolla, CA, USA) and OriginLabs (OriginLab Corporation, Northampton, MA, USA). Significance was set at $\mathrm{p}<0.05$.

\section{Results}

\section{Participants and disease characteristics}

During the study period of July 2021 to October 2021, $10 \mathrm{ME} / \mathrm{CFS}$ patients and 10 age- and sex-matched $\mathrm{HC}$ participated in this project. All ME/CFS patients reported symptoms fulfilling the CCC case definition and no other fatigue-related illness that may account 
for their symptoms. Table 1 includes demographic data of the participants. The average age of participants was $44.10 \pm 10.39$ and $43.90 \pm 10.71$ for $\mathrm{HC}$ and ME/CFS patients, respectively. All participants who volunteered in this project were female except $n=1$. The average BMI of $\mathrm{HC}$ were within normal range (18.5-24.9) measuring at $23.68 \pm 3.96$. While the average BMI of ME/CFS patients were above normal range at $25.74 \pm 5.49$. There was a significant difference in employment status between $\mathrm{HC}$ and ME/CFS patients $(\mathrm{p}=0.009)$. Six of the included ME/ CFS patients reported unemployment due to illness and/ or disability.

The SF-36 and WHO DAS surveys were used to assess QoL in ME/CFS patients compared with HC. As reported in Table 2, means scores were significantly reduced in ME/CFS patients across all SF-36 domains compared with HC. Lowest SF-36 scores in ME/CFS patients were observed in limitations due to physical role $(24.38 \pm 19.19)$. Mean domain scores for the WHO DAS show a significant increase in disability in ME/CFS patients compared with HC. ME/CFS patients reported greatest difficulty in ability to maintain life activities (66.87 \pm 24.66$)$. All blood parameters were within normal range according to Queensland Health Pathology.

All ME/CFS patients successfully completed the NCNED registry questionnaire. Data extracted from relevant questionnaire responses are presented Table 3. On average, patients were 26.7 years of age at the time of diagnosis and experienced symptoms of ME/CFS for

Table 1 Participant demographics

\begin{tabular}{llll}
\hline & HC & ME/CFS & P-value \\
\hline Age (years) & $44.10 \pm 10.39$ & $43.9 \pm 10.71$ & 0.853 \\
Gender n (\%) & & & $>0.9999$ \\
$\quad$ Female & $9(90.0 \%)$ & $9(90.0 \%)$ & \\
$\quad$ Male & $1(10.0 \%)$ & $1(10.0 \%)$ & \\
BMI (kg/m $\left.{ }^{2}\right)$ & $23.68 \pm 3.96$ & $25.74 \pm 5.49$ & 0.280 \\
Employment Status & & & \\
$\quad$ Full Time & $6(60.0 \%)$ & $2(20.0 \%)$ & $\mathbf{0 . 0 0 9 0}$ \\
$\quad$ Part Time & $3(30.0 \%)$ & $1(10.0 \%)$ & \\
$\quad$ Casual & $1(10.0 \%)$ & $1(10.0 \%)$ & \\
$\quad$ Unemployed & $0(0.0 \%)$ & $0(0.0 \%)$ & \\
$\quad$ Illness/disability & $0(0.0 \%)$ & $6(60.0 \%)$ & \\
Education & & & \\
$\quad$ Primary education & $0(0.0 \%)$ & $0(0.0 \%)$ & 0.9985 \\
$\quad$ High school & $0(0.0 \%)$ & $1(10.0 \%)$ & \\
$\quad$ Undergraduate & $5(50.0 \%)$ & $3(30.0 \%)$ & \\
Postgraduate/doctoral & $2(20.0 \%)$ & $4(40.0 \%)$ & \\
$\quad$ Other & $3(30.0 \%)$ & $2(20.0 \%)$ & \\
\hline
\end{tabular}

Values in bold are statistically significant

$H C$ healthy controls, ME Myalgic encephalomyelitis, CFS chronic fatigue syndrome, $B M I$ body mass index
17.7 years. Eight of the ten ME/CFS patients (80.0\%) included in this present study reported an infection prior to onset of symptoms. All ME/CFS patients (100\%) reported experiencing key symptoms of ME/ CFS including cognitive difficulties, body pain and sleep disturbances.

\section{Effect of PregS on calcium influx}

$\mathrm{Ca}^{2+}$ influx images were obtained from isolated human NK cells prior to overnight incubation with IL-2 and NTX (Fig. 1). TRPM3-dependent $\mathrm{Ca}^{2+}$ influx was stimulated by $50 \mu \mathrm{M}$ of PregS. While there was no significant difference reported for the slope of the $\mathrm{Ca}^{2+}$ influx curve between groups, the $T 1 / 2$ response $(\mathrm{p}<0.0001)$ and amplitude $(\mathrm{p}<0.0001)$ were significantly reduced in $\mathrm{ME} /$ CFS patients compared with HC. The inhibition of $50 \mu \mathrm{M}$ PregS by ononetin was also determined at baseline. Ononetin at a concentration of $4 \mu \mathrm{M}$ effectively blocked PregS stimulation of TRPM3, however there was no statistical significance between groups (Additional file 1: Figure S3.1).

\section{Effect of PregS on calcium influx after NTX treatment}

Human NK cells were incubated overnight supplemented with IL-2 with and without NTX (Fig. 2). Post-24 h, $\mathrm{Ca}^{2+}$ influx images were obtained from both control IL-2 stimulated cells and NTX treated cells. There was a significant reduction in slope $(\mathrm{p}<0.0001), \mathrm{T} 1 / 2$ response $(\mathrm{p}=0.0123)$ and amplitude $(\mathrm{p}<0.0001)$ in $\mathrm{ME} / \mathrm{CFS}$ patients compared with HC. There was no significant difference for NTX treated cells between groups for slope and $\mathrm{T} 1 / 2$ response. A significant increase in amplitude ( $\mathrm{p}<0.0001$ ) was reported in ME/CFS patients compared with HC following NTX treatment. The inhibition of $50 \mu \mathrm{M}$ PregS by ononetin was also determined following stimulation of NK cells with IL-2 and treatment using NTX. Ononetin at a concentration of $4 \mu \mathrm{M}$ effectively blocked PregS stimulation of TRPM3, however there was no statistical significance between groups (Additional file 1: Figure S3.2).

\section{Discussion}

We report, for the first time the significant reduction in $\mathrm{Ca}^{2+}$ influx via TRPM3 in NK cells in ME/CFS patients compared with $\mathrm{HC}$ using $\mathrm{Ca}^{2+}$ imaging technique. This current investigation provides novel findings for the rate, or speed, and insight into the maximum TRPM3dependent $\mathrm{Ca}^{2+}$ influx response in ME/CFS patients. Previous investigations have demonstrated TRPM3 channel dysfunction in isolated NK cells of ME/CFS patients compared with $\mathrm{HC}$ using the whole-cell patch clamp technique $[10,11]$. While patch-clamp is regarded as a gold standard technique for ion channel research, 
Table 2 Participant Quality of Life, disability scores and serology

\begin{tabular}{|c|c|c|c|}
\hline & $\mathrm{HC}$ & ME/CFS & P-value \\
\hline \multicolumn{4}{|l|}{ SF-36 (\%) } \\
\hline Physical functioning & $94.0 \pm 17.29$ & $37.5 \pm 30.93$ & $<0.0001$ \\
\hline Physical role & $95.0 \pm 11.71$ & $24.38 \pm 19.19$ & $<0.0001$ \\
\hline Pain & $90.25 \pm 20.83$ & $40.0 \pm 27.99$ & 0.003 \\
\hline General Health & $78.75 \pm 11.69$ & $29.59 \pm 18.37$ & $<0.0001$ \\
\hline Social functioning & $98.75 \pm 3.95$ & $27.5 \pm 26.22$ & $<0.0001$ \\
\hline Emotional role & $99.17 \pm 2.63$ & $69.99 \pm 23.31$ & 0.002 \\
\hline Emotional wellbeing & $76.96 \pm 11.04$ & $39.17 \pm 12.23$ & $<0.0001$ \\
\hline \multicolumn{4}{|l|}{ WHO DAS (\%) } \\
\hline Communication \& understanding & $1.62 \pm 2.09$ & $45.83 \pm 24.29$ & $<0.0001$ \\
\hline Mobility & $2.50 \pm 6.35$ & $56.0 \pm 30.26$ & $<0.0001$ \\
\hline Self-care & $0.0 \pm 0.0$ & $33.13 \pm 29.47$ & $<0.0001$ \\
\hline Interpersonal relationships & $1.25 \pm 10.62$ & $33.13 \pm 31.6$ & 0.009 \\
\hline Life activities & $6.25 \pm 10.62$ & $66.87 \pm 24.66$ & $<0.0001$ \\
\hline Participation in Society & $2.19 \pm 3.62$ & $57.49 \pm 23.11$ & $<0.0001$ \\
\hline \multicolumn{4}{|l|}{ Full blood count } \\
\hline White Cell Count $\left(\times 10^{9} / \mathrm{L}\right)$ & $5.97 \pm 0.79$ & $5.58 \pm 0.84$ & 0.247 \\
\hline Lymphocytes $\left(\times 10^{9} / \mathrm{L}\right)$ & $2.02 \pm 0.69$ & $1.60 \pm 0.42$ & 0.315 \\
\hline Neutrophils $\left(\times 10^{9} / L\right)$ & $3.37 \pm 0.69$ & $3.29 \pm 0.86$ & 0.684 \\
\hline Monocytes $\left(\times 10^{9} / L\right)$ & $0.44 \pm 0.10$ & $0.41 \pm 0.07$ & 0.436 \\
\hline Eosinophils $\left(\times 10^{9} / \mathrm{L}\right)$ & $0.14 \pm 0.11$ & $0.16 \pm 0.09$ & 0.579 \\
\hline Basophils $\left(\times 10^{9} / L\right)$ & $0.03 \pm 0.01$ & $0.04 \pm 0.01$ & 0.075 \\
\hline Platelets $\left(\times 10^{9} / L\right)$ & $250.40 \pm 55.41$ & $255.4 \pm 31.49$ & 0.684 \\
\hline Red Cell Count $\left(\times 10^{12} / \mathrm{L}\right)$ & $4.47 \pm 0.45$ & $4.47 \pm 0.34$ & 0.912 \\
\hline Haematocrit & $0.41 \pm 0.04$ & $0.41 \pm 0.03$ & 0.631 \\
\hline Haemoglobin (g/L) & $134.40 \pm 16.34$ & $135.4 \pm 11.71$ & 0.853 \\
\hline
\end{tabular}

Values in bold are statistically significant

HC healthy controls, ME Myalgic encephalomyelitis, CFS chronic fatigue syndrome, SF-36 36-item short form survey, WHO world health organization, DAS disability assessment schedule

TRPM3-dependent $\mathrm{Ca}^{2+}$ influx was not clear in our previous studies due to the small inward currents activated by PregS. Therefore, our data supports the characterisation of $\mathrm{Ca}^{2+}$ influx and TRPM3 activity for the pathomechanism of ME/CFS and the role for NTX as a potential intervention. The combination of electrophysiology and $\mathrm{Ca}^{2+}$ imaging protocols provides a comprehensive and complete analysis of TRPM3-dependent $\mathrm{Ca}^{2+}$ changes in NK cells of ME/CFS patients.

This current investigation reports a significant reduction in the T1/2 and amplitude of maximum TRPM3dependent $\mathrm{Ca}^{2+}$ responses in ME/CFS patients compared with $\mathrm{HC}$ at baseline. The reduction in TRPM3-dependent $\mathrm{Ca}^{2+}$ influx in ME/CFS patients compared with $\mathrm{HC}$ validates previous research which demonstrate significant loss in TRPM3 ion channel function [10, 11, 25]. Alterations in the profile of $\mathrm{Ca}^{2+}$ influx are strongly associated with significant physiological consequences. Changes in $\mathrm{Ca}^{2+}$ influx profiles play a critical role in determining the magnitude of $\mathrm{Ca}^{2+}$-dependent responses and are associated with physiological consequences [37]. It is hypothesised that TRPM3 ion channel dysfunction results in reduced $\mathrm{Ca}^{2+}$ influx in NK cells which has negative consequences on cytotoxic function in ME/CFS patients. Therefore, simultaneous reductions in amplitude and rate may augment effects of reduced $\mathrm{Ca}^{2+}$ concentration on cellular function and further research into $\mathrm{Ca}^{2+}$ mobilisation may elucidate the pathomechanism of ME/CFS.

Subsequently, the effect of IL-2 alone on $\mathrm{Ca}^{2+}$ influx was determined. The culturing of NK cells with the addition of IL-2 supports viability, preactivation, proliferation and development of cells; however, as IL-2 primes NK cells for activation this condition was used as a control for NTX treated cells [38]. The amplitude and T1/2 response were significantly reduced in IL-2 stimulated NK cells from ME/CFS patients compared with HC. Additionally, a significant reduction was reported for slope of $\mathrm{Ca}^{2+}$ influx in ME/CFS patients compared with $\mathrm{HC}$. It is interesting that significance was reported for 
Table 3 ME/CFS symptom characteristics

\begin{tabular}{lll}
\hline Age of diagnosis (Years [Mean \pm SD] $)$ & & $26.70 \pm 12.75$ \\
Disease duration (Years [Mean \pm SD] $)$ & & $17.70 \pm 14.95$ \\
Infectious onset, $n(\%)$ & Yes & $10(100 \%)$ \\
Cognitive difficulties & No & $0(0.0 \%)$ \\
& Yes & $10(100 \%)$ \\
Pain & No & $0(0 \%)$ \\
Sleep disturbances & Yes & $10(100 \%)$ \\
Sensory disturbances & No & $0(0 \%)$ \\
& Yes & $9(90.0 \%)$ \\
Immune disturbances & No & $1(10.0 \%)$ \\
Gastrointestinal disturbances & Yes & $9(90.0 \%)$ \\
Cardiovascular disturbances & No & $1(10.0 \%)$ \\
& Yes & $9(90.0 \%)$ \\
Respiratory disturbances & No & $1(10.0 \%)$ \\
Thermostatic instability & Yes & $8(80.0 \%)$ \\
& No & $2(20.0 \%)$ \\
Urinary disturbances & Yes & $8(90.0 \%)$ \\
& No & $2(20.0 \%)$ \\
& Yes & $10(100 \%)$ \\
NEM & No & $0(0 \%)$ \\
& Yes & $5(50.0 \%)$ \\
& No & $5(50.0 \%)$ \\
& &
\end{tabular}

ME Myalgic encephalomyelitis, CFS chronic fatigue syndrome, $S D$ standard deviation, $n$ number

slope of $\mathrm{Ca}^{2+}$ influx following IL-2 stimulation, but not at baseline. $\mathrm{Ca}^{2+}$ measurements differed between baseline and IL-2 stimulation conditions. Stimulation of NK cells with IL-2 is known to enhance NK cell cytotoxic function through $\mathrm{Ca}^{2+}$-dependent pathways [39, 40]. In a recent publication, the authors suggested a crosstalk between TRPM3- and IL-2-dependent cellular pathways leading to enhanced NK cell function in vitro [41]. It is therefore likely that changes in slope reported between baseline and IL-2 stimulation that are reflected in $\mathrm{HC}$ indicate that pathways involved in TRPM3 and IL-2 signalling may promote $\mathrm{Ca}^{2+}$ mobilisation in NK cells. The consistent reduction in amplitude and T1/2 of response reported in this current investigation suggests that TRPM3 dysfunction reported in ME/CFS patients impairs sufficient $\mathrm{Ca}^{2+}$ entry in NK cells. Changes in ion channel function may be a consequence of an unstable open channel [42] and channel stability may be a component to consider in future research.

$\mathrm{Ca}^{2+}$ has a critical and beneficial role in promoting the activation of $\mathrm{NK}$ cell function as previous investigations using $\mathrm{Ca}^{2+}$ blockers have led to a significant reduction in NK cell cytotoxicity $[43,44]$. The coupling between receptor and ligand initiates a $\mathrm{Ca}^{2+}$-dependent cascade that relies on sustained and long-term influx of the cation. $\mathrm{Ca}^{2+}$ facilitates the phosphorylation and activation of protein kinases such as Ras, P38, phosphatidylinositol 4,5-bisphosphate 3-kinase (PI3K) and mitogen activation protein kinases (MAPK) by enabling proteinprotein and protein-phosphatase interactions [45-47]. The significant reduction in phosphorylation of protein kinases has been reported in activated NK cells of ME/ CFS patients [48]. Therefore, changes in $\mathrm{Ca}^{2+}$ can either enhance, or in the case of ME/CFS, impair protein kinase phosphorylation, thus impacting functional outcomes such as cytokine production and cytotoxicity. Moreover, phosphatidylinositol 4,5-bisphosphate $\left(\mathrm{PIP}_{2}\right)$ is a critical component of numerous signalling pathways including PI3K signalling and $\mathrm{Ca}^{2+}$ mobilisation. The function of TRPM3 also relies on the presence and binding of PIP [49]. A recent publication reported a potential association between TRPM3 dysfunction and the involvement of $\mathrm{PIP}_{2}$ in the pathomechanism of ME/CFS [41]. Therefore, TRPM3 dysfunction may contribute to ME/CFS pathomechanism due to consequences of impaired $\mathrm{Ca}^{2+}$ signalling, including impeding $\mathrm{Ca}^{2+}$-dependent cellular pathways that result in impaired NK cells function that is consistently reported in literature.

Under homeostatic conditions, the activation of TRPM3 leads to an increase in cytosolic $\mathrm{Ca}^{2+}$ that is important for regulating numerous biological processes including but not limited to temperature and pain sensation, insulin secretion and vascular smooth muscle contraction [50]. Furthermore, ion channels are located on different organelles throughout cells, and mitochondrial dysfunction reported in ME/CFS patients may be attributable to ion channel dysfunction, namely TRPM3 [51]. In NK cells, store-operated $\mathrm{Ca}^{2+}$ entry (SOCE) is a primary form of $\mathrm{Ca}^{2+}$ regulation [52]. However, it is possible that TRPM3 monitors intracellular $\mathrm{Ca}^{2+}$ levels in lymphocytes in addition to SOCE, as observed in oligodendrocytes $[53,54]$. This current investigation did not aim to assess the activity of SOCE and therefore further investigation on the relationship between TRPM3 and SOCE in NK cells is proposed. It is important to outline that within the N-terminal of TRPM3 there are two calmodulin $(\mathrm{CaM})$ binding sites. CaM senses changes in $\left[\mathrm{Ca}^{2+}\right]_{\mathrm{I}}$ to either up- or down-regulate TRPM3 activity $[55,56]$. The interaction of CaM and TRPM3 suggests strong activity in $\mathrm{Ca}^{2+}$ sensing that may be augmented by $\mathrm{Ca}^{2+}$ store depletion or by stimulation of GPCRs [57]. The activity of CaM in TRPM3 function has not been investigated in ME/CFS patients but provides an interesting target for future research to determine any problems in TRPM3-dependent $\mathrm{Ca}^{2+}$ homeostasis.

Currently, there is no universal treatment to improve symptoms of ME/CFS. However, new technologies may provide future avenues to further assist in characterising 


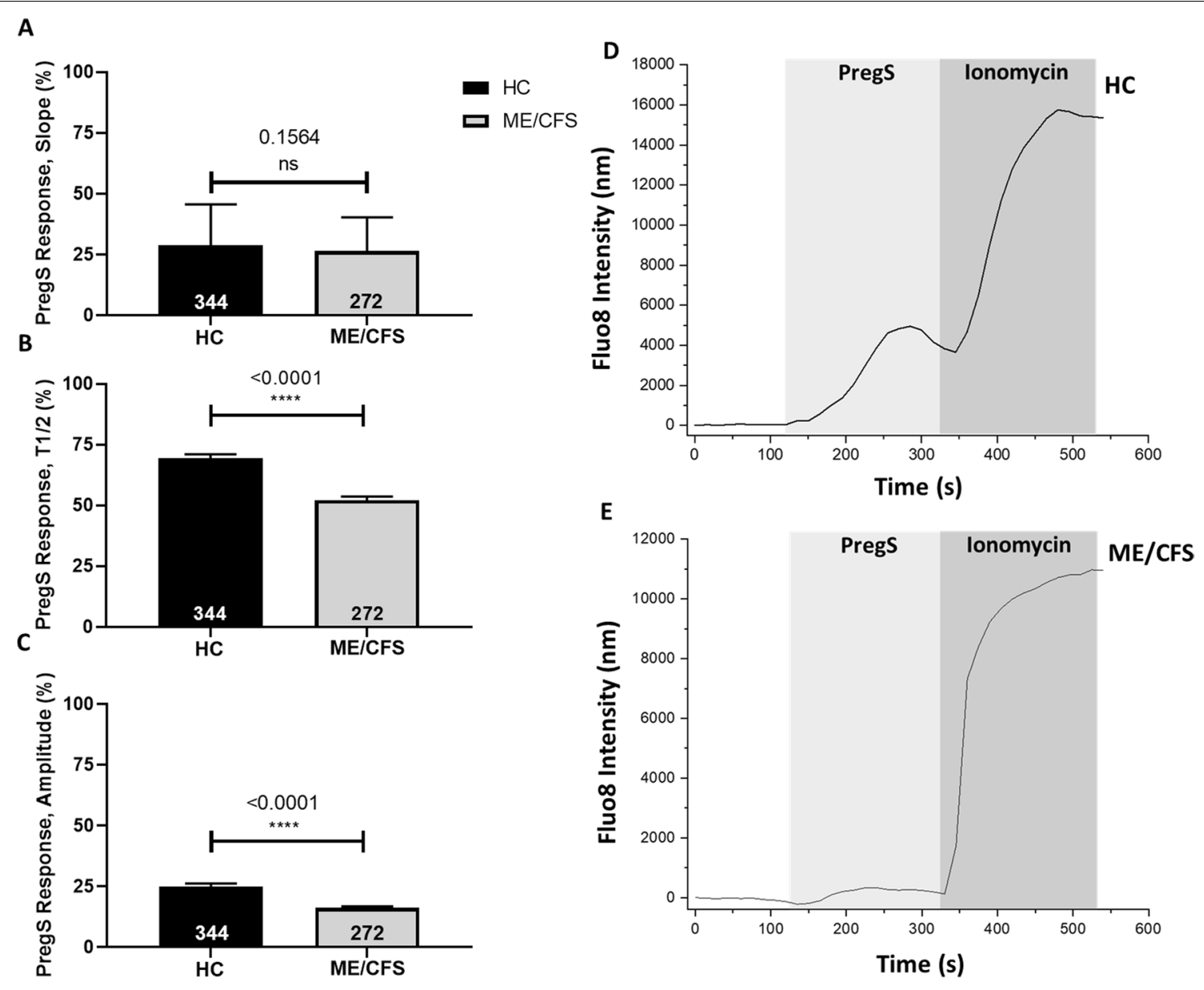

Fig. 1 Stimulation of NK cells by $50 \mu \mathrm{M}$ PregS at baseline prior to overnight stimulation with IL-2 and treatment with NTX. A Proportional mean data from $\mathrm{Ca}^{2+}$ imaging experiments comparing normalised slope of $50 \mu \mathrm{M}$ PregS $\mathrm{Ca}^{2+}$ influx curve. B Proportional mean data from $\mathrm{Ca}^{2+}$ imaging experiments comparing normalised T1/2 (seconds) response of maximum $50 \mu \mathrm{M}$ PregS $\mathrm{Ca}^{2+}$ response. C Proportional mean data from $\mathrm{Ca}^{2+}$ imaging experiments comparing normalised amplitude $(\mathrm{nm})$ of maximum $50 \mu \mathrm{M}$ PregS $\mathrm{Ca}^{2+}$ response. D Example time-course responses to $50 \mu \mathrm{M}$ PregS and $1 \mu \mathrm{M}$ lonomycin in HC. E Example time-course responses to $50 \mu \mathrm{M}$ PregS and $1 \mu \mathrm{M}$ lonomycin in ME/CFS patients. Data was collected from $n=10 \mathrm{HC}$ and $n=10 \mathrm{ME} / \mathrm{CFS}$ patients. All $\mathrm{Ca}^{2+}$ influx measurements for PregS were normalised using lonomycin response curves. Total number of cells following the removal of outliers are included within bar graphs. Data presented as mean $\pm S D$. HC healthy controls, ME myalgic encephalomyelitis, CFS chronic fatigue syndrome, T1/2 half-time, nm nanometres, PregS, pregnenolone sulfate, SD standard deviation, $n s$ no significance

TRPM3 dysfunction and impaired $\mathrm{Ca}^{2+}$ mobilisation in ME/CFS research. Recent electrophysiology investigations have reported the restoration of TRPM3 function following in vitro treatment of isolated NK cells with NTX [25]. In this current investigation we report the restoration of TRPM3-dependent $\mathrm{Ca}^{2+}$ influx following in vitro treatment of isolated NK cells overnight with NTX. The cellular mechanism involves the inhibition of $\mu \mathrm{OR}$ which would otherwise inhibit the activation of TRPM3 channels [28, 58]. Therefore, by negating the inhibitory action of $\mu \mathrm{OR}$, it is hypothesised that this restores TRPM3 function, thus reinstating
TRPM3-dependent $\mathrm{Ca}^{2+}$ influx in NK cells from ME/ CFS patients.

The expression of $\mu \mathrm{OR}$ has been reported in lymphocytes where they are important in the inflammatory pain response [59]. The activation of $\mu \mathrm{OR}$ by certain endogenous and synthetic opioids leads to immunosuppression [60, 61, 61, 62]. Administration of the synthetic opioid, morphine, has resulted in a significant reduction in NK cell cytotoxic activity in rats, mice and humans [63-65]. Interestingly, NTX inhibits the suppressive activity of morphine on NK cells through the $\mu \mathrm{OR}$ [66]. Research has reported that ME/CFS patients secrete insufficient opioid peptides that regulate pain and release of 

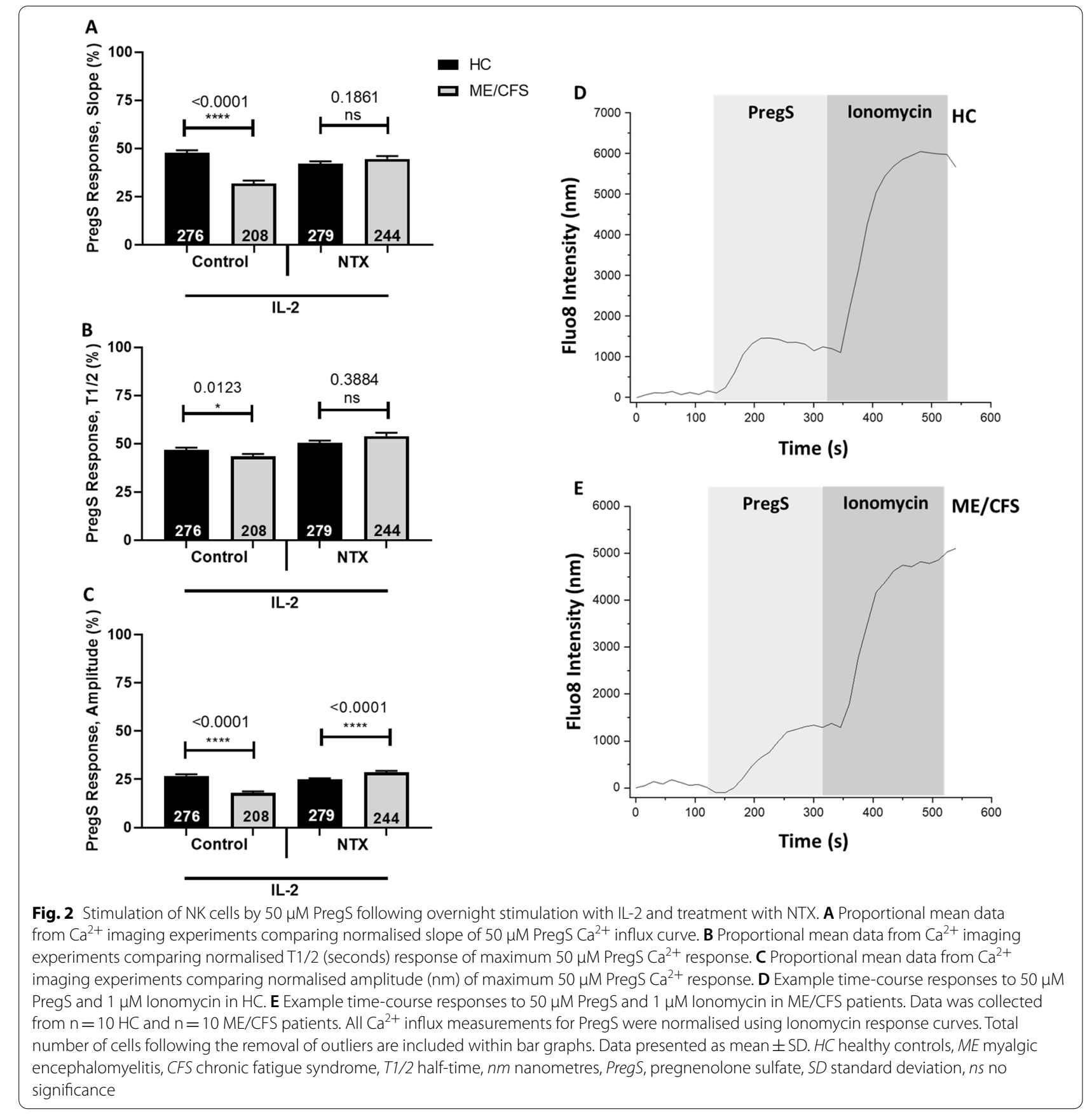

cytokines [31]. Beta-endorphins ( $\beta$-EP) are an endogenous opioid neuropeptide produced by many cell types including lymphocytes. The release of $\beta$-EP from lymphocytes are regulated by the activity of $\mu \mathrm{OR}$ resulting in changes to cell proliferation and immune function [67]. Interestingly, within a specific dosage window of $1-5 \mathrm{mg} /$ day, it is reported that LDN increases $\beta$-EP release in NK cells resulting in increased cytotoxic activity $[68,69]$. An investigation by Conti and colleagues found significantly reduced $\beta$-EP in ME/CFS patients reflecting chronic immune activation [69]. Therefore, targeting OR, with NTX, on immune cells may resolve NK cell dysfunction through ion channel regulation such as the indirect effects seen with TRPM3. Future research may aim to investigate NK cell cytotoxicity in ME/CFS patients following in vitro treatment with NTX.

TRPM3 function has previously been assessed in a group of ME/CFS patients who routinely administer 
LDN daily [31]. ME/CFS patients who take LDN yielded similar TRPM3 function to $\mathrm{HC}$ and no significant differences between groups were observed [31]. Medical data from a cohort of 218 ME/CFS patients administering LDN reported a positive treatment response in $73.9 \%$ of responders [24]. In a separate investigation, self-reported retrospective comparison of ME/CFS symptoms before and after LDN commencement suggested an improvement in cognitive symptoms and immune disturbances [31]. Moreover, studies with fibromyalgia patients have found that LDN significantly reduced pain, fatigue, sleep disturbances, headaches and gastrointestinal issues [70]. Collectively, these results suggest there is potential therapeutic benefit of LDN to treat TRPM3 dysfunction in ME/CFS patients.

\section{Conclusion}

ME/CFS is a serious and chronic condition that affects multiple organ systems of the human body. TRPM3 dysfunction has been consistently found in NK cells of ME/CFS, with consequential implications for $\mathrm{Ca}^{2+}$ signalling and cell function. TRPM3-dependent $\mathrm{Ca}^{2+}$ influx was significantly reduced in NK cells of ME/ CFS patients compared with HC. In this current investigation the treatment of isolated NK cells with NTX restored TRPM3-dependent $\mathrm{Ca}^{2+}$ influx in ME/CFS patients to the extent that $\mathrm{Ca}^{2+}$ influx measurements were either similar to $\mathrm{HC}$ or significantly increased. This investigation provides additional evidence for the potential therapeutic benefit of NTX for ME/CFS.

\begin{abstract}
Abbreviations
$\beta$-EP: Beta endorphins; $\mu$ : $\mathrm{Mu} ; \mathrm{Ca}^{2+}$ : Calcium; $\left[\mathrm{Ca}^{2+}\right]_{\mid}$: Intracellular calcium concentration; CaM: Calmodulin; CCC: Canadian Consensus Criteria; CFS: Chronic fatigue syndrome; CNS: Central nervous system; CRAC: Calcium release activated channel; DAS: Disability assessment schedule; DRG: Dorsal root ganglia; EDTA: Ethylenediaminetetraacetic acid; ERK: Extracellular-signal-release kinase; GPCR: G protein coupled receptors; HC: Healthy controls; ICC: International Consensus Criteria; IL-2: Interleukin 2; IP : Inositol 1,3 bisphosphate; LDN: Low dose naltrexone; MAPK: Mitogen activated protein kinase; ME: Myalgic encephalomyelitis; NK: Natural killer; NTX: Naltrexone hydrochloride; OR: Opioid receptor; PBMC: Peripheral blood mononuclear cells; PI3K: Phosphatidylinositol 4,5-bisphosphate 3-kinase; PIP 2 : Phosphatidylinositol 4,5-bisphosphate; PLC: Protein lipase C; PregS: Pregnenolone sulfate; QoL: Quality of life; SD: Standard deviation; SF-36: 36 Item short form healthy survey; SOCE: Store operated calcium entry;T1/2: Half-time; TRPM3: Transient receptor potential melastatin 3; WHO: World Health Organization.
\end{abstract}

\section{Supplementary Information}

The online version contains supplementary material available at https://doi. org/10.1186/s12967-022-03297-8.

Additional file 1. Supplementary figures.

\section{Acknowledgements}

The authors would like to acknowledge those who volunteered their time and blood sample for this project. We acknowledge Dr Leonardo Lucantoni (Technical Partners Health) for microscopy support, in particular with the live cell imaging.

\section{Authors' contributions}

NE-F performed all experiments, data analysis and writing of the manuscript. NE-F, SDP, HC, DS and SM-G designed the project. HC, DS, SM-G and SDP participated in study coordination and critically reviewed this manuscript. KM oversaw data analysis and critically reviewed study design. All authors read and approved the final manuscript.

\section{Funding}

Funding bodies included: the Stafford Fox Medical Research Foundation (489798), the National Health and Medical Research Council (1199502), McCusker Charitable Foundation (49979), lan and Talei Stewart, Buxton Foundation (4676), Henty Community (4879), Henty Lions Club (4880), Mason Foundation (47107), Mr Douglas Stutt, Blake Beckett Trust Foundation (4579), Alison Hunter Memorial Foundation (4570), and the Change for ME Charity (4575).

\section{Data availability}

Datasets analysed and/or generated during the current study are not publicly available due to confidentiality agreements but are available from the corresponding author upon reasonable request.

\section{Declarations}

\section{Ethics approval and consent to participate}

This project was approved by Griffith University Human Research Ethics Committee (GU:2019/1005) and Gold Coast University Hospital Human Research Ethics Committee (HREC/2019/QGC/56469). All participants provided written consent prior to participation.

\section{Competing interests}

The authors declare that they have no competing interests.

\section{Author details}

${ }^{1}$ School of Pharmacy and Medical Sciences, Griffith University, Gold Coast, Australia. ${ }^{2}$ National Centre for Neuroimmunology and Emerging Diseases, Menzies Health Institute Queensland, Griffith University, Gold Coast, Australia. ${ }^{3}$ Consortium Health International for Myalgic Encephalomyelitis, Griffith University, Gold Coast, Australia. ${ }^{4}$ Université de Paris, INSERM U944 and CNRS UMR 7212, Institut de Recherche Saint Louis, Hôpital Saint Louis, APHP, 75010 Paris, France. ${ }^{5}$ Laboratory of Cellular Pharmacology, School of Pharmacy, AichiGakuin University, Nagoya, Japan.

Received: 3 December 2021 Accepted: 4 February 2022 Published online: 16 February 2022

\section{References}

1. Flockerzi V, Nilius B. TRPs: Truly Remarkable Proteins. In: Nilius B, Flockerzi V, editors. Mamm. Transient Recept. Potential TRP Cation Channels Vol. I, Berlin, Heidelberg: Springer; 2014, p. 1-12. https://doi.org/10.1007/ 978-3-642-54215-2_1

2. Oberwinkler J, Lis A, Giehl KM, Flockerzi V, Philipp SE. Alternative splicing switches the divalent cation selectivity of TRPM3 channels. J Biol Chem. 2005;280:22540-8. https://doi.org/10.1074/jbc.M503092200.

3. Grimm C, Kraft R, Sauerbruch S, Schultz G, Harteneck C. Molecular and functional characterization of the melastatin-related cation channel TRPM3. J Biol Chem. 2003;278:21493-501. https://doi.org/10.1074/jbc. M300945200.

4. Owsianik G, Talavera K, Voets T, Nilius B. Permeation and selectivity of TRP channels. Annu Rev Physiol. 2006;68:685-717. https://doi.org/10.1146/ annurev.physiol.68.040204.101406.

5. Wagner TFJ, Loch S, Lambert S, Straub I, Mannebach S, Mathar I, et al. Transient receptor potential M3 channels are ionotropic steroid receptors 
in pancreatic beta cells. Nat Cell Biol. 2008;10:1421-30. https://doi.org/10. 1038/ncb1801.

6. Straub I, Mohr F, Stab J, Konrad M, Philipp SE, Oberwinkler J, et al. Citrus fruit and fabacea secondary metabolites potently and selectively block TRPM3. Br J Pharmacol. 2013;168:1835-50. https://doi.org/10.1111/bph. 12076.

7. Berridge MJ, Bootman MD, Roderick HL. Calcium: Calcium signalling: dynamics, homeostasis and remodelling. Nat Rev Mol Cell Biol. 2003:4:517-29. https://doi.org/10.1038/nrm1155.

8. Nguyen T, Staines D, Nilius B, Smith P, Marshall-Gradisnik S. Novel identification and characterisation of Transient receptor potential melastatin 3 ion channels on Natural Killer cells and B lymphocytes: effects on cell signalling in Chronic fatigue syndrome/Myalgic encephalomyelitis patients. Biol Res. 2016:49:27. https://doi.org/10.1186/s40659-016-0087-2.

9. Nguyen T, Johnston S, Clarke L, Smith P, Staines D, Marshall-Gradisnik S. Impaired calcium mobilization in natural killer cells from chronic fatigue syndrome/myalgic encephalomyelitis patients is associated with transient receptor potential melastatin 3 ion channels. Clin Exp Immunol. 2017;187:284-93. https://doi.org/10.1111/cei.12882.

10. Cabanas H, Muraki K, Eaton N, Balinas C, Staines D, Marshall-Gradisnik S. Loss of Transient Receptor Potential Melastatin 3 ion channel function in natural killer cells from Chronic Fatigue Syndrome/Myalgic Encephalomyelitis patients. Mol Med. 2018;24:44. https://doi.org/10.1186/ s10020-018-0046-1.

11. Cabanas H, Muraki K, Balinas C, Eaton-Fitch N, Staines D, Marshall-Gradisnik S. Validation of impaired Transient Receptor Potential Melastatin 3 ion channel activity in natural killer cells from Chronic Fatigue Syndrome/ Myalgic Encephalomyelitis patients. Mol Med. 2019;25:14. https://doi.org/ 10.1186/s10020-019-0083-4

12. Kloc M, Kubiak JZ, Li XC, Ghobrial RM. The newly found functions of MTOC in immunological response. J Leukoc Biol. 2014;95:417-30. https:// doi.org/10.1189/jlb.0813468.

13. Orrenius S, Zhivotovsky B, Nicotera P. Regulation of cell death: the calcium-apoptosis link. Nat Rev Mol Cell Biol. 2003;4:552-65. https://doi. org/10.1038/nrm1150.

14. Berridge MJ. Calcium signalling remodelling and disease. Biochem Soc Trans. 2012;40:297-309. https://doi.org/10.1042/BST20110766.

15. Carruthers BM, Jain AK, Meirleir KLD, Peterson DL, Klimas NG, Lerner AM, et al. Myalgic Encephalomyelitis/Chronic Fatigue Syndrome. J Chronic Fatigue Syndr. 2003;11:7-115. https://doi.org/10.1300/J092v11n01_02.

16. Carruthers BM, van de Sande MI, Meirleir KLD, Klimas NG, Broderick G, Mitchell T, et al. Myalgic encephalomyelitis: International Consensus Criteria. J Intern Med. 2011;270:327-38. https://doi.org/10.1111/j.1365-2796. 2011.02428.x

17. Eaton-Fitch N, du Preez S, Cabanas H, Staines D, Marshall-Gradisnik S. A systematic review of natural killer cells profile and cytotoxic function in myalgic encephalomyelitis/chronic fatigue syndrome. Syst Rev. 2019;8:279. https://doi.org/10.1186/s13643-019-1202-6.

18. Marshall-Gradisnik S, Huth T, Chacko A, Johnston S, Smith P, Staines D. Natural killer cells and single nucleotide polymorphisms of specific ion channels and receptor genes in myalgic encephalomyelitis/chronic fatigue syndrome. Appl Clin Genet. 2016;9:39-47. https://doi.org/10. 2147/TACG.S99405.

19. Balinas C, Cabanas H, Staines D, Marshall-Gradisnik S. Transient receptor potential melastatin 2 channels are overexpressed in myalgic encephalomyelitis/chronic fatigue syndrome patients. J Transl Med. 2019. https:// doi.org/10.1186/s12967-019-02155-4.

20. Larkins RG, Molesworth SR. Chronic fatigue syndrome clinical practice guidelines. Med J Aust. 2002;177:51-2. https://doi.org/10.5694/j.13265377.2002.tb04640.x.

21. Vriens J, Voets T. Sensing the heat with TRPM3. Pflugers Arch. 2018:470:799-807. https://doi.org/10.1007/s00424-017-2100-1.

22. Montell C, Birnbaumer L, Flockerzi V. The TRP channels, a remarkably functional family. Cell. 2002;108:595-8. https://doi.org/10.1016/s0092 8674(02)00670-0.

23. Jason LA, Richman JA, Rademaker AW, Jordan KM, Plioplys AV, Taylor RR, et al. A community-based study of chronic fatigue syndrome. Arch Intern Med. 1999;159:2129-37. https://doi.org/10.1001/archinte.159.18.2129.

24. Polo O, Pesonen P, Tuominen E. Low-dose naltrexone in the treatment of myalgic encephalomyelitis/chronic fatigue syndrome (ME/CFS). Fatigue
Biomed Health Behav. 2019;7:207-17. https://doi.org/10.1080/21641846. 2019.1692770.

25. Cabanas H, Muraki K, Staines D, Marshall-Gradisnik S. Naltrexone restores impaired transient receptor potential melastatin 3 ion channel function in natural killer cells from myalgic encephalomyelitis/chronic fatigue syndrome patients. Front Immunol. 2019. https://doi.org/10.3389/fimmu. 2019.02545.

26. Niciu MJ, Arias AJ. Targeted opioid receptor antagonists in the treatment of alcohol use disorders. CNS Drugs. 2013;27:777-87. https://doi.org/10. 1007/s40263-013-0096-4.

27. Tuteja N. Signaling through $G$ protein coupled receptors. Plant Signal Behav. 2009:4:942-7.

28. Dembla S, Behrendt M, Mohr F, Goecke C, Sondermann J, Schneider FM, et al. Anti-nociceptive action of peripheral mu-opioid receptors by G-beta-gamma protein-mediated inhibition of TRPM3 channels. ELife. 2017. https://doi.org/10.7554/eLife.26280.

29. Weerts EM, Kim YK, Wand GS, Dannals RF, Lee JS, Frost JJ, et al. Differences in $\delta$ - and $\mu$-opioid receptor blockade measured by positron emission tomography in naltrexone-treated recently abstinent alcohol-dependent subjects. Neuropsychopharmacology. 2008;33:653-65. https://doi.org/10 1038/sj.npp.1301440.

30. Bao Y, Gao Y, Yang L, Kong X, Yu J, Hou W, et al. The mechanism of $\mu$-opioid receptor (MOR)-TRPV1 crosstalk in TRPV1 activation involves morphine anti-nociception, tolerance and dependence. Channels. 2015;9:235-43. https://doi.org/10.1080/19336950.2015.1069450.

31. Cabanas H, Muraki K, Eaton-Fitch N, Staines DR, Marshall-Gradisnik S. Potential Therapeutic Benefit of Low Dose Naltrexone in Myalgic Encephalomyelitis/Chronic Fatigue Syndrome: Role of Transient Receptor Potential Melastatin 3 lon Channels in Pathophysiology and Treatment. Front Immunol. 2021. https://doi.org/10.3389/fimmu.2021.687806.

32. Ware JE. SF-36 health survey update. Spine. 2000;25:3130-9. https://doi. org/10.1097/00007632-200012150-00008.

33. WHO |WHO Disability Assessment Schedule 2.0 (WHODAS 2.0). WHO n.d. http://www.who.int/classifications/icf/whodasii/en/. Accessed May 8, 2020.

34. Panda SK, Ravindran B. Isolation of Human PBMCs Bio-Protoc. 2013. https://doi.org/10.21769/BioProtoc.323.

35. Beeler TJ, Jona I, Martonosi A. The effect of ionomycin on calcium fluxes in sarcoplasmic reticulum vesicles and liposomes. J Biol Chem. 1979;254:6229-31.

36. Prakriya M, Lewis RS. Store-Operated Calcium Channels. Physiol Rev. 2015:95:1383-436. https://doi.org/10.1152/physrev 00020.2014.

37. Park D, Dunlap K. Dynamic Regulation of Calcium Influx by G-Proteins, Action Potential Waveform, and Neuronal Firing Frequency. J Neurosci. 1998;18:6757-66. https://doi.org/10.1523/JNEUROSCl.18-17-06757.1998.

38. Wu Y, Tian Z, Wei H. Developmental and Functional Control of Natural Killer Cells by Cytokines. Front Immunol. 2017. https://doi.org/10.3389/ fimmu.2017.00930

39. Gasteiger G, Hemmers S, Firth MA, Le Floch A, Huse M, Sun JC, et al. IL-2dependent tuning of NK cell sensitivity for target cells is controlled by regulatory T cells. J Exp Med. 2013;210:1167-78. https://doi.org/10.1084/ jem.20122462.

40. Mills GB, Cheung RK, Grinstein S, Gelfand EW. Interleukin 2-induced lymphocyte proliferation is independent of increases in cytosolic-free calcium concentrations. J Immunol. 1985;134:2431-5.

41. Eaton-Fitch N, Cabanas H, du Preez S, Staines D, Marshall-Gradisnik S. The effect of IL-2 stimulation and treatment of TRPM3 on channel co-localisation with PIP2 and NK cell function in myalgic encephalomyelitis/chronic fatigue syndrome patients. J Transl Med. 2021;19:306. https://doi.org/10. 1186/s12967-021-02974-4.

42. Zhao S, Yudin Y, Rohacs T. Disease-associated mutations in the human TRPM3 render the channel overactive via two distinct mechanisms. ELife 9: e55634. Doi: https://doi.org/10.7554/eLife.55634.

43. Redmond J, O'Rilley D, Buchanan P. Role of ion channels in natural killer cell function towards cancer. Discov Med. 2017;23:353-60.

44. Chitwood K, Heim-Duthoy K. Immunosuppressive properties of calcium channel blockers. Pharmacotherapy. 1993;13:447-54.

45. Lanier LL. Up on the tightrope: natural killer cell activation and inhibition. Nat Immunol. 2008:9:495-502. https://doi.org/10.1038/ni1581.

46. Lanier LL. Natural killer cell receptor signaling. Curr Opin Immunol. 2003;15:308-14. https://doi.org/10.1016/s0952-7915(03)00039-6. 
47. Chuderland D, Seger R. Calcium regulates ERK signaling by modulating its protein-protein interactions. Commun Integr Biol. 2008;1:4-5.

48. Huth TK, Staines D, Marshall-Gradisnik S. ERK1/2, MEK1/2 and p38 downstream signalling molecules impaired in CD56dimCD16+ and CD56brightCD16dim/- natural killer cells in Chronic Fatigue Syndrome/ Myalgic Encephalomyelitis patients. J Transl Med. 2016. https://doi.org/ 10.1186/s12967-016-0859-z.

49. Tóth BI, Konrad M, Ghosh D, Mohr F, Halaszovich CR, Leitner MG, et al. Regulation of the transient receptor potential channel TRPM3 by phosphoinositides. J Gen Physiol. 2015;146:51-63. https://doi.org/10.1085/jgp. 201411339.

50. Thiel G, Rubil S, Lesch A, Guethlein LA, Rössler OG. Transient receptor potential TRPM3 channels: Pharmacology, signaling, and biological functions. Pharmacol Res. 2017;124:92-9. https://doi.org/10.1016/j.phrs.2017. 07.014 .

51. Holden S, Maksoud R, Eaton-Fitch N, Cabanas H, Staines D, MarshallGradisnik S. A systematic review of mitochondrial abnormalities in myalgic encephalomyelitis/chronic fatigue syndrome/systemic exertion intolerance disease. J Transl Med. 2020;18:290. https://doi.org/10.1186/ s12967-020-02452-3.

52. Oh-hora M, Rao A. Calcium signaling in lymphocytes. Curr Opin Immunol. 2008;20:250-8. https://doi.org/10.1016/j.coi.2008.04.004.

53. Papanikolaou M, Lewis A, Butt AM. Store-operated calcium entry is essential for glial calcium signalling in CNS white matter. Brain Struct Funct. 2017;222:2993-3005. https://doi.org/10.1007/s00429-017-1380-8.

54. Verkhratsky A, Parpura V. Store-operated calcium entry in neuroglia. Neurosci Bull. 2014;30:125-33. https://doi.org/10.1007/s12264-013-1343-x.

55. Przibilla J, Dembla S, Rizun O, Lis A, Jung M, Oberwinkler J, et al. Ca2+dependent regulation and binding of calmodulin to multiple sites of Transient Receptor Potential Melastatin 3 (TRPM3) ion channels. Cell Calcium. 2018:73:40-52. https://doi.org/10.1016/j.ceca.2018.03.005.

56. Holendova B, Grycova L, Jirku M, Teisinger J. Ptdlns(4,5)P2 interacts with CaM binding domains on TRPM3 N-terminus. Channels. 2012;6:479-82. https://doi.org/10.4161/chan.22177.

57. Lee N, Chen J, Sun L, Wu S, Gray KR, Rich A, et al. Expression and characterization of human transient receptor potential melastatin 3 (hTRPM3). J Biol Chem. 2003;278:20890-7. https://doi.org/10.1074/jbc.M211232200.

58. Badheka D, Yudin Y, Borbiro I, Hartle CM, Yazici A, Mirshahi T, et al. Inhibition of Transient Receptor Potential Melastatin 3 ion channels by G-protein By subunits. ELife. 2017. https://doi.org/10.7554/eLife.26147.

59. Eisenstein TK. The role of opioid receptors in immune system function. Front Immunol. 2019. https://doi.org/10.3389/fimmu.2019.02904.

60. McCarthy L, Szabo I, Nitsche JF, Pintar JE, Rogers TJ. Expression of functional mu-opioid receptors during T cell development. J Neuroimmunol. 2001;114:173-80. https://doi.org/10.1016/s0165-5728(01)00248-x.

61. Maher DP, Walia D, Heller NM. Suppression of human natural killer cells by different classes of opioids. Anesth Analg. 2019;128:1013-21. https://doi. org/10.1213/ANE.0000000000004058.

62. Fuggetta MP, Di Francesco P, Falchetti R, Cottarelli A, Rossi L, Tricarico M, et al. Effect of morphine on cell-mediated immune responses of human lymphocytes against allogeneic malignant cells. J Exp Clin Cancer Res CR. 2005;24:255-63.

63. Franchi S, Panerai AE, Sacerdote P. Buprenorphine ameliorates the effect of surgery on hypothalamus-pituitary-adrenal axis, natural killer cell activity and metastatic colonization in rats in comparison with morphine or fentanyl treatment. Brain Behav Immun. 2007;21:767-74. https://doi.org/ 10.1016/j.bbi.2007.01.001.

64. Sacerdote P, Manfredi B, Mantegazza P, Panerai AE. Antinociceptive and immunosuppressive effects of opiate drugs: a structure-related activity study. Br J Pharmacol. 1997;121:834-40. https://doi.org/10.1038/sj.bjp. 0701138.

65. Yeager MP, Colacchio TA, Yu CT, Hildebrandt L, Howell AL, Weiss J, et al. Morphine inhibits spontaneous and cytokine-enhanced natural killer cell cytotoxicity in volunteers. Anesthesiology. 1995;83:500-8. https://doi.org/ 10.1097/00000542-199509000-00008.

66. Shavit Y, Martin FC, Yirmiya R, Ben-Eliyahu S, Terman GW, Weiner H, et al. Effects of a single administration of morphine or footshock stress on natural killer cell cytotoxicity. Brain Behav Immun. 1987;1:318-28. https:// doi.org/10.1016/0889-1591(87)90034-1.
67. Gilman S, Feldman J, Milner R, Bloom F, Feldman J. Beta-Endorphin enhances lymphocyte proliferative responses. PNAS. 1982;79:5. https:// doi.org/10.1073/pnas.79.13.4226.

68. Boyadjieva N, Dokur M, Advis JP, Meadows GG, Sarkar DK. Chronic ethanol inhibits NK cell cytolytic activity: role of opioid peptide $\beta$-endorphin. J Immunol. 2001;167:5645-52. https://doi.org/10.4049/jimmunol.167.10. 5645.

69. Conti F, Pittoni V, Sacerdote P, Priori R, Meroni PL, Valesini G. Decreased immunoreactive beta-endorphin in mononuclear leucocytes from patients with chronic fatigue syndrome. Clin Exp Rheumatol. 1998;16:729-32.

70. Cote B, Ross B, Fortner J, Rao D. The use and utility of low-dose naltrexone capsules for patients with fibromyalgia. Int J Pharm Compd. 2018:22:252-6.

\section{Publisher's Note}

Springer Nature remains neutral with regard to jurisdictional claims in published maps and institutional affiliations.
Ready to submit your research? Choose BMC and benefit from:

- fast, convenient online submission

- thorough peer review by experienced researchers in your field

- rapid publication on acceptance

- support for research data, including large and complex data types

- gold Open Access which fosters wider collaboration and increased citations

- maximum visibility for your research: over $100 \mathrm{M}$ website views per year

At BMC, research is always in progress.

Learn more biomedcentral.com/submissions 